\title{
HUBUNGAN ANTARA KARAKTERISTIK PENDERITA DENGAN DERAJAT ASMA BRONKIAL DI RUMAH SAKIT UMUM DAERAH ANDI MAKKASAU KOTA PAREPARE
}

\section{Effect of Student Boarding Conditions on the Chance of Tuberculosis in the City of Parepare}

Andi Khaidir, Usman, Henni Kumaladewi Hengky

Program Studi Kesehatan Masyarakat Fakultas Ilmu Kesehatan Universitas Muhammadiyah Parepare (pikmgenetik@gmail.com, 085399408569)

\begin{abstract}
ABSTRAK
Asma merupakan gangguan inflamasi kronis di jalan napas. Dasar penyakit ini adalah hiperaktivitas bronkus dan obstruksi jalan napas. Gejala asma adalah gangguan pernapasan (sesak), batuk produktif terutama pada malam hari atau menjelang pagi, dan dada terasa tertekan. Tujuan penelitian ini untuk menunjukkan apakah umur, jenis kelamin, pendidikan terakhir, tingkat pendapatan, faktor genetik dan lingkungan mempengaruhi derajat asma bronkial di Rumah Sakit Umum Daerah Andi Makkasau Kota Parepare. Metode yang digunakan dalam penelitian ini adalah metode analitik dengan pendekatan Cross Sectional Survey. Peneliti mengidentifikasi melalui observasional dengan menggunakan kuesioner pada sampel, dimana sampel dalam penelitian ini sebanyak 60 orang. Data dianalisis secara univariat dan bivariat menggunakan uji statistik Chi Square melalui SPSS Versi 24. Hasil penelitian menunjukkan bahwa umur $(0,000)$, pendidikan terakhir $(0,011)$, tingkat pendapatan $(0,017)$, faktor genetik $(0,037)$ dan lingkungan $(0,017)$ berpengaruh terhadap derajat asma bronchial sedangkan jenis kelamin $(0,875)$ tidak berpengaruh terhadap Derajat Asma Bronkial di Rumah Sakit Umum Daerah Andi Makkasau Kota Parepare. Berdasarkan hasil penelitian yang diperoleh, diharapkan bagi penderita asma sebaiknya rajin melakukan pengontrolan kesehatan sehingga derajat asma tidak semakin parah.
\end{abstract}

\section{Kata Kunci : Derajat asma bronkial, genetik, lingkungan}

\begin{abstract}
Asthma is a chronic inflammatory disorder in the airway. The basis of this disease is bronchial hyperactivity and airway obstruction. Symptoms of asthma are respiratory problems (tightness), productive cough especially at night or before morning, and the chest feels depressed. The purpose of this study is to show whether age, gender, education, income level, genetic and environmental factors affect the degree of bronchial asthma in Andi Makkasau Regional General Hospital, Parepare City. The method used in this study is an analytical method with a Cross Sectional Survey approach. The researcher identified through observational using a questionnaire on the sample, where the sample in this study were 60 people. Data were analyzed by univariate and bivariate using Chi Square statistical tests through SPSS Version 24. The results showed that age $(0,000)$, last education $(0,011)$, income level $(0,017)$, genetic factors $(0,037)$ and environment $(0,017)$ affected the degree of bronchial asthma while gender $(0,875)$ did not affect the degree of bronchial asthma at home Regional Public Hospital Andi Makkasau Parepare City. Based on the results of the research obtained, it is expected that asthma sufferers should be diligent in controlling their health so that the degree of asthma is not getting worse.
\end{abstract}

Keywords: Degree of bronchial, genetic, environmental asthma 


\section{PENDAHULUAN}

Asma merupakan gangguan inflamasi kronis di jalan napas. Dasar penyakit ini adalah hiperaktivitas bronkus dan obstruksi jalan napas. Gejala asma adalah gangguan pernapasan (sesak), batuk produktif terutama pada malam hari atau menjelang pagi, dan dada terasa tertekan. Faktor risiko terjadinya asma merupakan interaksi antara faktor penjamu (host factor) dan faktor lingkungan. Faktor penjamu termasuk predisposisi genetik. Faktor lingkungan yang berpengaruh adalah alergen, sensitisasi lingkungan kerja, asap rokok, polusi udara, infeksi pada pernapasan, diet, status sosial ekonomi maupun besarnya keluarga individu yang kecenderungan lalu berkembang menjadi asma dan menyebabkan terjadinya eksaserbasi dan atau menyebabkan gejala-gejala asma yang menetap. ${ }^{1}$

Angka kejadian penyakit asma akhirakhir ini mengalami peningkatan dan relative sangat tinggi dengan banyaknya morbiditas dan mortalitas. World Health Organization (WHO) tahun 2013 memperkirakan 100-150 juta penduduk dunia saat ini terkena penyakit asma dan diperkirakan akan mengalami penambahan 180.000 setiap tahunnya. ${ }^{2}$ Hampir separuh dari seluruh pasien asma pernah dirawat di rumah sakit dan melakukan kunjungan ke bagian gawat darurat setiap tahunnya, berdasarkan laporan NCHS (National Center For Health Statistics) tahun 2010 terdapat 4,447 kematian yang disebabkan oleh penyakit asma atau sekitar $6,5 \%$ dari total populasi. ${ }^{3}$

Penyakit asma masuk dalam sepuluh besar penyebab kesakitan dan kematian di Indonesia. Berdasarkan jumlah kunjungan pasien Rawat Jalan dan Rawat Inap di RSUD Andi Makkasau Parepare mulai dari tahun 2014 sampai 2016 diperoleh data tentang jumlah penderita penyakit asma yang melakukan pemeriksaan diantaranya, pada tahun 2014 terdapat 105 penderita yang melakukan kujungan rawat jalan sedangkan kunjungan rawat inap terdapat 53 pasien Lakilaki dan 74 pasien wanita. Pada tahun 2015 hanya terdapat 16 kunjungan rawat jalan dan kunjungan rawat inap sebanyak 108 pasien dengan jumlah laki-laki 57 orang dan perempuan 51 orang. Sedangkan di tahun 2016 terdapat peningkatan pasien rawat jalan yaitu sebayak 74 kunjungan dan terdapat 71 pengunjung di rawat inap yang meliputi 32 orang laki-laki dan 39 orang perempuan. ${ }^{4}$

Faktor risiko asma dibagi menjadi dua, faktor risiko yang berhubungan dengan terjadinya asma dan faktor risiko yang berhubungan dengan terjadinya eksaserbasi atau serangan asma yang disebut faktor pencetus. Faktor risiko yang mencetuskan terjadinya asma bronkial diantaranya asap rokok, tungau debu rumah, polusi udara, perubahan cuaca, dan jenis makanan. Asap rokok dapat menyebabkan asma, baik pada perokok itu sendiri maupun orangorang yang terkena asap rokok. Suatu penelitian di 
Finlandia menunjukkan bahwa orang dewasa yang terkena asap rokok berpeluang menderita asma dua kali lipat dibandingkan orang yang tidak terkena asap rokok. Studi lain menunjukkan bahwa seseorang penderita asma yang terkena asap rokok selama satu jam, maka akan mengalami sekitar 20\% kerusakan fungsi paru. Pada anak-anak, asap rokok akan memberikan efek lebih parah dibandingkan orang dewasa, ini disebabkan lebar saluran pernafasan anak lebih sempit, sehingga jumlah nafas anak akan lebih cepat dari orang dewasa.

Akibatnya, jumlah asap rokok yang masuk ke dalam saluran pernapasan menjadi lebih banyak dibanding berat badannya. Selain itu, karena sistem pertahanan tubuh yang belum berkembang, munculnya gejala asma pada anak-anak jauh lebih cepat dibanding orang dewasa. Tungau debu rumah adalah hewan (Dermatophagoides Pteronyssinus) yang sangat kecil sekitar $0,5 \mathrm{~mm}$ yang umum di jumpai di tempat tinggal manusia. Tungau debu rumah biasanya berada di karpet dan jok kursi yang kotor, terutama yang berbulu tebal dan lama tidak dibersihkan, juga dari tumpukan koran, buku, pakaian yang kotor. Tungau debu rumah yang menyerang penderita asma bronkial disebabkan oleh masuknya suatu alergen ke dalam saluran napas seseorang sehingga merangsang terjadinya reaksi hipersensitivitas tipe I atau reaksi alergi. Polusi udara adalah suatu keadaan dimana udara mengandung bahan kimia, partikel, organisme hidup lainnya yang menyebabkan kerugian atau ketidaknyamanan pada manusia.

Polusi udara di bagi menjadi 2 yaitu Polusi udara dalam ruangan dapat menimbulkan ancaman kesehatan yang serius, seperti semprotan minyak wangi, semprotan nyamuk, debu dalam lemari, dan lain-lain. Menurut Studi EPA (Environment Protecting Agency) menunjukkan bahwa tingkat polusi udara sebanyak 2-5 kali lebih tinggi udara dalam ruangan dibandingkan udara luar ruangan. $^{5}$

Tingkat tingginya polusi udara dalam ruangan menjadi perhatian khusus, karena banyak orang yang menghabiskan sebanyak 90 persen dari waktu mereka di dalam ruangan. Efek kesehatan polusi udara dalam ruangan bisa menjadi lebih buruk bagi orangorang dengan gangguan pernapasan seperti asma. Kualitas udara di luar ruangan merupakan masalah kesehatan masyarakat yang utama. Di luar ruangan, seperti polusi akibat zat kimia hasil pabrikan, kendaraan bermotor, dan orang yang bekerja di lingkungan berdebu atau asap dapat memicu serangan sesak napas yang berkepanjangan. Polusi udara di luar ruangan memberikan efek yang merugikan kesehatan seperti penyakit jantung, kanker, asma, penyakit pernapasan, dan bahkan kematian.

Paling berisiko dari polusi udara di luar ruangan adalah anak-anak, remaja, orang dewasa yang lebih tua, dan orang dengan penyakit paru-paru, seperti asma dan penyakit 
paru obstruktif kronis. Kondisi cuaca yang berlawanan seperti temperatur dingin, tingginya kelembaban dapat menyebabkan asma lebih parah, epidemik yang dapat membuat asma menjadi lebih parah berhubungan dengan badai dan meningkatnya konsentrasi partikel alergenik. Dimana partikel tersebut dapat menyapu pollen sehingga terbawa oleh air dan udara. Perubahan tekanan atmosfer dan suhu memperburuk asma dengan serangan sesak napas dan pengeluaran lendir yang berlebihan. Ini umum terjadi ketika kelembaban tinggi, hujan, badai selama musim dingin. Udara yang kering dan dingin menyebabkan sesak di saluran pernafasan.

Penderita asma berisiko mengalami reaksi anafilaksis akibat alergi makanan fatal yang dapat mengancam jiwa. Makanan yang terutama sering mengakibatkan reaksi yang fatal tersebut adalah kacang, ikan laut dan telur. Alergi makanan seringkali tidak terdiagnosis sebagai salah satu pencetus asma meskipun penelitian membuktikan alergi makanan sebagai pencetus bronkokontriksi pada anak. Serangan asma ditandai adanya kalor (panas karena vasodilatasi), rubor (kemerahan karena vasodilatasi), tumor (eksudasi plasma dan edema), dolor (rasa sakit karena rangsang sensoris), dan functio laesa (fungsi terganggu). Gejala-gejala tersebut dapat ditemukan pada penderita asma tanpa membedakan penyebabnya baik yang alergik maupun non alergik. Baik asma yang alergik maupun non alergik ditemukan adanya inflamasi dan hiperaktivitas saluran napas. Gambaran klinis asma klasik adalah serangan episodik batuk, mengi, dan sesak napas. Pada awal serangan sering gejala tidak jelas seperti rasa berat di dada, dan pada asma alergik mungkin disertai pilek atau bersin. Terlebih lagi pasien asma alergik juga memberikan gejala terhadap faktor pencetus non alergik seperti asap rokok, asap yang merangsang, infeksi saluran napas atas ataupun perubahan cuaca. Batuk di malam hari atau sesak dada merupakan keluhan yang sering ditampilkan. Mengi merupakan suara siulan tinggi melengking saat menghembuskan napas.

Berdasarkan kondisi tersebut maka penulis tertarik untuk mengetahui lebih dalam mengenai Asma Bronkial dengan meneliti Hubungan Antara Karakteristik Penderita dengan Derajat Asma Bronkial di Rumah Sakit Umum Daerah Andi Makkasau Kota Parepare.

\section{BAHAN DAN METODE}

Metode penelitian yang digunakan adalah analitik dengan rancangan penelitian cross sectional survey. Penelitian ini dilaksanakan di Rumah Sakit Umum Andi Makkasau Kota Parepare, berlangsung pada bulan Juni 2018. Instrumen dalam penelitian yang digunakan adalah kuesioner untuk mengukur derajat asma penderita serta menggunakan data rekam medis penyakit asma di Rumah Sakit Umum Daerah Andi Makkasau Parepare. Teknik Pengumpulan 
data primer dilakukan menggunakan kuesioner dimana pasien menjawab pertanyaan yang diajukan pada kuesioner. Data sekunder diperoleh dengan pengambilan data yang telah ada dari dokumen hasil rekam medik pasien asma. pasien yang melakukan kujungan Rawat Jalan di Rumah Sakit Umum Daerah Andi Makkasau Parepare pada tahun 2016 dengan jumlah kunjungan sebanyak 145 responden. ${ }^{4}$ Teknik Penarikan sampel dalam penelitian ini dilakukan menggunakan non probability sampling (non random sampling) dengan tehnik purposive sampling. Analisis univariat untuk melihat distribusi frekuensi variabel, yaitu memperoleh informasi secara umum tentang semua variabel penelitian. Analisis bivariat digunakan untuk menguji hubungan variabel Dependen dan Independen. Analisis bivariat dilakukan dengan Uji Chi Square untuk menguji hipotesis yang ada. Dasar pengambilan keputusan penerimaan hipotesis penelitian berdasarkan tingkat signifikan (nilai $p)$, dimana terdapat hubungan (bermakna) apabila nilai $\mathrm{p}<0,05$ dan tidak ada hubungan apabila $\mathrm{p}>0,05$.

\section{HASIL}

Tabel 1 menunjukkan bahwa dari 100 reponden yang terpilih, responden yang mempunyai Umur Dewasa : 26-45 Tahun sebanyak $(24,0 \%)$ dan yang mempunyai Umur Lansia : > 45 Tahun sebanyak (36,0\%). Responden dengan jenis kelamin Laki-laki sebanyak (27,0\%) dan Jenis Kelamin Perempuan sebanyak 33,0\%. Responden dengan Pendidikan Tinggi sebanyak (28,0\%) dan dengan Pendidikan Rendah sebanyak $(32,0 \%)$. Sedangkan responden yang memiliki Tingkat Pendapatan Tinggi : $\geq$ Rp.2.600.000 sebanyak $(42,0 \%)$ dan yang memiliki Tingkat Pendapatan Rendah : <Rp.2.600.000 sebanyak $(18,0 \%)$. Sedangkan responden yang Ada Faktor Genetik sebanyak $(30,0 \%)$ dan yang Tidak Ada Faktor Genetik (30,0\%). Serta responden Lingkungan yang menpengaruhi sebanyak (40,0\%) dan yang Lingkungan Tidak Mempengaruhi (20,0\%).

Tabel 2 menunjukkan bahwa dari 34 responden yang menderita Asma Berat $(12,5 \%)$ Berumur Dewasa 26-45 tahun dan $(86,1 \%)$ Berumur Lansia $>45$ tahun. Sedangkan dari 26 responden menderita Asma Ringan (87,5\%) Berumur Dewasa 26-45 tahun dan $(13,9 \%)$ Berumur Lansia >45 tahun. Berdasarkan hasil uji chi-square di peroleh nilai $p(0,000)<\alpha(0,05)$, maka $\mathrm{H}_{\mathrm{a}}$ diterima dan $\mathrm{H}_{0}$ ditolak sehingga disimpulkan bahwa ada pengaruh Hubungan Umur dengan Derajat Asma yang dilakukan di Rumah Sakit Umum Daerah Andi Makkasau Kota Parepare.

Tabel 3 menunjukkan bahwa dari 15 responden yang menderita Asma Berat $(55,6 \%)$ Laki-laki dan $(57,6 \%)$ Perempuan. Sedangkan dari 26 responden menderita Asma Ringan (44,4\%) Laki-laki dan $(42,4 \%)$ Perempuan. Berdasarkan hasil uji chi-square di peroleh nilai $p(0,875)>\alpha(0,05)$, maka $\mathrm{H}_{\mathrm{a}}$ diterima dan $\mathrm{H}_{0}$ ditolak sehingga disimpulkan bahwa tidak ada pengaruh Hubungan Jenis 
Kelamin dengan Derajat Asma yang dilakukan di Rumah Sakit Umum Daerah Andi Makkasau Daerah Kota Parepare.

Tabel 4 menunjukkan bahwa dari 11 responden yang menderita Asma Berat (39,3\%) Pendidikan Tinggi dan (71,9\%) Pendidikan Rendah. Sedangkan dari 26 responden menderita Asma Ringan (60,7\%) Pendidikan Tinggi dan $(42,4 \%)$ Pendidikan Rendah. Berdasarkan hasil uji chi-square di peroleh nilai $p(0,011)<\alpha(0,05)$, maka $\mathrm{H}_{\mathrm{a}}$ diterima dan $\mathrm{H}_{0}$ ditolak sehingga disimpulkan bahwa ada pengaruh Hubungan Tingkat Pendidikan dengan Derajat Asma yang dilakukan di Rumah Sakit Umum Daerah Andi Makkasau Daerah Kota Parepare.

Tabel 5 menunjukkan bahwa dari 34 responden yang menderita Asma Berat (66,7\%) dengan Tinggi >Rp.2.600.000 dan $(33,3 \%)$ Rendah <Rp.2.600.000. Sedangkan dari 26 responden menderita Asma Ringan $(33,3 \%)$ Tinggi $\geq$ Rp.2.600.000 dan $(66,7 \%)$ Rendah <Rp.2.600.000. Berdasarkan hasil uji chi-square di peroleh nilai $p(0,017)<\alpha$ $(0,05)$, maka $\mathrm{H}_{\mathrm{a}}$ diterima dan $\mathrm{H}_{0}$ ditolak sehingga disimpulkan bahwa ada pengaruh Hubungan Tingkat Pendapatan dengan Derajat Asma yang dilakukan di Rumah Sakit Umum Daerah Andi Makkasau Daerah Kota Parepare.

Tabel 6 menunjukkan bahwa dari 21 responden yang menderita Asma Berat (70,0\%) Ada dan (43,3\%) Tidak Ada. Sedangkan dari 26 responden menderita Asma
Ringan (30,0\%) Ada dan (56,7\%) Tidak Ada. Berdasarkan hasil uji chi-square di peroleh nilai $p(0,037)<\alpha(0,05)$, maka $\mathrm{H}_{\mathrm{a}}$ diterima dan $\mathrm{H}_{0}$ ditolak sehingga disimpulkan bahwa ada pengaruh Hubungan Faktor Genetik dengan Derajat Asma yang dilakukan di Rumah Sakit Umum Daerah Andi Makkasau Daerah Kota Parepare.

Tabel 7 menunjukkan bahwa dari 34 responden yang menderita Asma Berat (67,5\%) Mempengaruhi dan (35,0\%) Tidak Mempengaruhi. Sedangkan dari 26 responden menderita Asma Ringan (32,5\%) Mempengaruhi dan (65,0\%) Tidak Mempengaruhi. Berdasarkan hasil uji chisquare di peroleh nilai $p(0,017)<\alpha(0,05)$, maka $\mathrm{H}_{\mathrm{a}}$ diterima dan $\mathrm{H}_{0}$ ditolak sehingga disimpulkan bahwa ada pengaruh Hubungan Lingkungan dengan Derajat Asma yang dilakukan di Rumah Sakit Umum Daerah Andi Makkasau Daerah Kota Parepare.

\section{PEMBAHASAN}

Asma merupakan problem kesehatan diseluruh dunia, yang mempengaruhi kurang lebih $1-18 \%$ populasi berbagai negara di dunia. Angka kematian di dunia akibat asma diperkirakan mencapai 250.000 orang pertahun. Penyakit ini merupakan salah satu penyakit utama yang menyebabkan pasien memerlukan perawatan, baik di rumah sakit maupun di rumah. Separuh dari semua kasus asma berkembang sejak masa sebelum umur 40 tahun. Namun demikian, asma dapat 
dimulai pada segala usia, mempengaruhi pria dan wanita tanpa kecuali dan bisa terjadi pada setiap orang pada segala etnis. ${ }^{4}$

Berdasarkan hasil uji chi-square di peroleh nilai $p(0,000)<\alpha(0,05)$, maka $\mathrm{H}_{\mathrm{a}}$ diterima dan $\mathrm{H}_{0}$ ditolak sehingga disimpulkan bahwa ada pengaruh Hubungan Umur dengan Derajat Asma yang dilakukan di Rumah Sakit Umum Andi Makkasau Daerah Kota Parepare. Hasil Penelitian menunjukkan bahwa dari 34 responden yang menderita Asma Berat (12,5\%) Berumur Dewasa 26-45 tahun dan $(86,1 \%)$ Berumur Lansia >45 tahun. Sedangkan dari 26 responden menderita Asma Ringan (87,5\%) Berumur Dewasa 26-45 tahun dan $(13,9 \%)$ Berumur Lansia $>45$ tahun. Pada saat dilakukannya penelitian ini rata-rata responden yang ditemukan berada pada usia lansia ( $\geq 45$ tahun) pada usia ini asma yang diderita responden mengalami tingkat keparahan lanjut. Pada usia lansia ini diketahui bahwa asma sering saja lebih parah, hal ini disebabkan karena pada usia tersebut terjadi penyempitan pada saluran napas, penyempitan saluran napas menyebabkan asma semakin parah.

Pada penelitian didapatkan hasil pada usia lansia mengalami berada pada kategori asma tidak terkontrol hal ini sesuai dengan teori yang menyatakan bahwa pada usia lanjut sulit dilakukan diagnosis pada asma selain itu asma pada usia lanjut juga sulit dikendalikan karena responden cenderung menjalani banyak perawatan untuk penyakit lain yang diderita. ${ }^{5}$
Hal inilah yang juga cenderung menyebabkan ditemukannya hubungan antara umur dengan derajat asma, sebab bila asma semakin parah maka derajat asma juga semakin berat.

Jenis kelamin merupakan salah satu faktor yang dapat mempengaruhi tingkat kontrol asma di Rumah Sakit Umum Daerah Andi Makkasau Kota Parepare. Dalam menyebabkan asma jenis kelamin merupakan salah satu hal yang merupakan faktor risiko dimana pada kriteria laki-laki usia muda lebih rentan terkena penyakit asma dibandingkan pada kelompok perempuan tetapi pada kelompok usia dewasa risiko terkena asma sama besar dan pada usia 40 tahun asma pada perempuan lebih tinggi. Hal ini disebabkan karena ukuran saluran pernapasan pada lakilaki muda lebih kecil dan berbanding terbalik pada usia $>40$ tahun. $^{4}$

Berdasarkan hasil uji chi-square di peroleh nilai $p(0,875)>\alpha(0,05)$, maka $\mathrm{H}_{\mathrm{a}}$ diterima dan $\mathrm{H}_{0}$ ditolak sehingga disimpulkan bahwa tidak ada pengaruh Hubungan Jenis Kelamin dengan Derajat Asma yang dilakukan di Rumah Sakit Umum Andi Makkasau Daerah Kota Parepare. Hasil Penelitian Menunjukkan bahwa dari 15 responden yang menderita Asma Berat (55,6\%) Laki-laki dan (57,6\%) Perempuan. Sedangkan dari 26 responden menderita Asma Ringan (44,4\%) Laki-laki dan $(42,4 \%)$ Perempuan. Pada penelitian ini tidak didapatkan hubungan antara jenis kelamin dengan derajat asma 
dimana rata-rata responden berjenis kelamin perempuan yang menderita derajat asma berat $(57,6 \%)$. Salah satu faktor yang mempengaruhi tingginya asma pada perempuan di RSUD Andi Makkasau Kota Parepare karena kecenderungan perempuan untuk memeriksakan kesehatan lebih tinggi hal ini dapat disebabkan karena aktifitas yang kurang pada perempuan. Faktor lain yang menyebabkan tidak didapatkannya hubungan karena jumlah proporsi responden perempuan lebih besar dibandingkan laki-laki yang juga dapat berpengaruh terhadap uji statistik yang dilakukan peneliti. Hal lain yang dapat mempengaruhi tidak ditemukannya hubungan antara jenis kelamin dengan derajat asma sebab pada usia > 40 tahun perempuan lebih rentan terkena asma dan tingkat keparahan semakin tinggi

Pada penelitian yang dilakukan oleh Widi Atmoko dkk (2013) yang menemukan hubungan mengatakan bahwa adanya hubungan ditemukan dikarenakan perempuan lebih sering memiliki asma yang tidak terkontrol berhubungan dengan cara perempuan melaporkan gejalanya, bahwa perempuan lebih sering mencari pengobatan ke Rumah Sakit, hal ini digambarkan pada jumlah responden perempuan pada Rumah Sakit Persahabatan Jakarta sebanyak 69 orang dengan presentasi cukup tinggi $(64,5 \%){ }^{6}$

Pengetahuan tentang asma merupakan hasil dari tahu dan ini terjadi setelah orang melakukan penginderaan suatu objek tertentu baik melalui penglihatan, pendengaran, penciuman, rasa dan raba. Sebagian besar pengetahuan manusia diperoleh dari pendidikan, pengalaman sendiri maupun pengalaman orang lain, media masa maupun lingkungan sesuai dengan teori pengetahuan menurut Notoatmodjo (2007). ${ }^{7}$

Berdasarkan hasil uji chi-square di peroleh nilai $p(0,011)<\alpha(0,05)$, maka $\mathrm{H}_{\mathrm{a}}$ diterima dan $\mathrm{H}_{0}$ ditolak sehingga disimpulkan bahwa ada pengaruh Hubungan Tingkat Pendidikan dengan Derajat Asma yang dilakukan di Rumah Sakit Umum Andi Makkasau Daerah Kota Parepare. Hasil penelitian menunjukkan bahwa dari 11 responden yang menderita Asma Berat (39,3\%) Pendidikan Tinggi dan (71,9\%) Pendidikan Rendah. Sedangkan dari 26 responden menderita Asma Ringan (60,7\%) Pendidikan Tinggi dan $(42,4 \%)$ Pendidikan Rendah. Dalam penelitian ini menunjukkan bahwa sebagian besar pengetahuan 71,9\% responden dalam kategori Pendidikan Rendah. Pengetahuan yang diperoleh salah satunya disebabkan oleh faktor pendidikan, dimana rata-rata pendidikan responden adalah SD dan SMP. Hal ini sesuai dengan penelitian yang dilakukan oleh Wolagole (2012) bahwa tingkat pendidikan responden mempunyai peran cukup tinggi terhadap kemampuan responden dalam memahami tentang asma. Pengalaman menderita asma dalam kurun waktu yang lama berdampak pada 
pengetahuan responden, dalam memahami penyakitnya. ${ }^{8}$

Penelitian ini terdapat $71,9 \%$ responden berpengetahuan kurang, hal ini disebabkan kurangnya penyuluhan-penyuluhan yang diterima masyarakat. Beberapa responden menyatakan belum pernah mendapatkan penyuluhan tentang asma. Masyarakat relatif kurang berinteraksi dengan orang lain sehingga kondisi ini menyebabkan informasi yang mereka terima relatif kecil. Menurut penelitian yang dilakukan oleh Wardani (2012) pengetahuan kurang disebabkan kurangnya kesadaran masyarakat untuk mendapatkan informasi tentang asma yang bersumber dari media cetak. Hal inilah yang menyebabkan pengetahuan mereka tentang asma menjadi kurang. ${ }^{9}$

Pendapatan adalah semua penghasilan yang didapat oleh keluarga baik berupa uang ataupun jasa. Masyarakat yang mempunyai penghasilan kecil, maka hasil dari pekerjaannya hanya untuk memenuhi kebutuhan sehari-hari. Keluarga yang berpenghasilan menengah, lebih terarah kepada pemenuhan kebutuhan pokok yang layak seperti makan, pakaian, perumahan, pendidikan dan lain-lain, sedangkan keluarga yang berpenghasilan tinggi dan berkecukupan, dapat memenuhi segala keinginan yang mereka inginkan.

Berdasarkan hasil uji chi-square di peroleh nilai $p(0,017)<\alpha(0,05)$, maka $\mathrm{H}_{\mathrm{a}}$ diterima dan $\mathrm{H}_{0}$ ditolak sehingga disimpulkan bahwa ada pengaruh Hubungan Tingkat Pendapatan dengan Derajat Asma yang dilakukan di Rumah Sakit Umum Andi Makkasau Daerah Kota Parepare. Hasil penelitian menunjukkan bahwa dari 34 responden yang menderita Asma Berat (66,7\%) dengan Tinggi $\geq$ Rp.2.600.000 dan $(33,3 \%)$ Rendah <Rp.2.600.000. Sedangkan dari 26 responden menderita Asma Ringan $(33,3 \%)$ Tinggi $>$ Rp.2.600.000 dan $(66,7 \%)$ Rendah <Rp.2.600.000. Hasil penelitian terdapat pengaruh hubungan Tingkat Pendapatan dengan derajat asma. Semakin tinggi penghasilan keluarga maka semakin mudah dalam mencukupi kebutuhan seharihari dan kebutuhan lainnya, sebaliknya semakin rendah penghasilan keluarga maka semakin sulit keluarga dalam memenuhi kebutuhan sehari-hari dan kebutuhan lainnya.

Sejalan dengan hasil penelitian Irawan dan Windi (2012) menyebutkan bahwa, adanya perbedaan yang bermakna pada pasien asma dan tidak asma dengan status ekonomi rendah. Penghasilan yang rendah meningkatkan risiko asma terkait dengan kondisi perumahan yang buruk. ${ }^{10}$ Penelitian yang sesuai juga dilakukan oleh Fattore et al., (2015) menyebutkan bahwa anak dari keluarga yang berstatus sosial ekonomi rendah lebih berisiko mengalami situasi stres dan kejadian penyakit yang berat. Situasi tersebut mengembangkan perilaku negatif atau tidak sehat oleh sebagian anggota keluarga. ${ }^{11}$ 
Faktor Genetik/keturunan yaitu faktor yang dapat terjadi pada semua orang dan semua golongan umur sejak bayi sampai berusia lanjut, risiko terbesar terjadi pada anak yang diturunkan oleh orang tuanya. Misalnya anak menderita penyakit asma ternyata mempunyai orang tua (ayah/ibu) atau saudara (kakak,adik,bibi) yang menderita asma. ${ }^{9}$

Berdasarkan hasil uji chi-square di peroleh nilai $p(0,037)<\alpha(0,05)$, maka $\mathrm{H}_{\mathrm{a}}$ diterima dan $\mathrm{H}_{0}$ ditolak sehingga disimpulkan bahwa ada pengaruh Hubungan Faktor Genetik dengan Derajat Asma yang dilakukan di Rumah Sakit Umum Andi Makkasau Daerah Kota Parepare. Hasil Penelitian menunjukkan bahwa dari 21 responden yang menderita Asma Berat (70,0\%) Ada dan $(43,3 \%)$ Tidak Ada. Sedangkan dari 26 responden menderita Asma Ringan (30,0\%) Ada dan (56,7\%) Tidak Ada. Hasil penelitian adanya riwayat keturunan penyakit asma bronkial, merupakan salah satu faktor risiko penyebab menurunnya penyakit asma pada anggota keluarganya.

Hal ini dibuktikan dengan penelitian yang dilakukan oleh Purnomo (2008). Adanya riwayat penyakit asma bronkial, mempunyai tiga kali lipat lebih tinggi jika riwayat keturunan dengan asma disertai dengan salah satu atopi. Melihat hasil analisi multivariat kejadian asma bronkial pada responden memiliki nilai OR ; 8,27 (95\% CI : 1,50545,434) dengan $p=0,015$. Hasil tersebut menginformasikan bahwa keluarga yang mempunyai riwayat penyakit asma bronkial mempunyai 8,27 kali dibandingkan dengan keluarga yang tidak memiliki riwayat penyakit asma bronkial. ${ }^{12}$

Faktor lingkungan yang berpengaruh adalah alergen, sensitisasi lingkungan kerja, asap rokok, polusi udara, infeksi pada pernapasan, diet, status sosial ekonomi maupun besarnya keluarga individu yang kecenderungan lalu berkembang menjadi asma dan menyebabkan terjadinya eksaserbasi dan atau menyebabkan gejala-gejala asma yang menetap. ${ }^{1}$

Berdasarkan hasil uji chi-square di peroleh nilai $p(0,017)<\alpha(0,05)$, maka $\mathrm{H}_{\mathrm{a}}$ diterima dan $\mathrm{H}_{0}$ ditolak sehingga disimpulkan bahwa ada pengaruh Hubungan Lingkungan dengan Derajat Asma yang dilakukan di Rumah Sakit Umum Andi Makkasau Daerah Kota Parepare. Hasil Penelitian menunjukkan bahwa dari 34 responden yang menderita Asma Berat (67,5\%) Mempengaruhi dan (35,0\%) Tidak Mempengaruhi. Sedangkan dari 26 responden menderita Asma Ringan (32,5\%) Mempengaruhi dan (65,0\%) Tidak Mempengaruhi. Hasil penelitian adanya faktor-faktor yang dapat menimbulkan kekambuhan asma atau sering disebut sebagai faktor pencetus salah satunya yaitu lingkungan.

Hal ini sejala dengan penelitian dari hasil analisis data statistik menunjukkan bahwa terdapat hubungan antara lingkungan dengan kejadian Asma bronkial di wilayah 
kerja Puskesmas Tamalate kota Gorontalo dengan $p$ value $0,000 .{ }^{10}$ Penderita Asma dapat terserang bahan - bahan pencetus ini secara tidak sengaja misalnya debu rumah tangga, debu kasur/bantal kapuk, ataupun karena hobi atau karena pekerjaan atau profesi. ${ }^{11}$

\section{KESIMPULAN DAN SARAN}

Berdasarkan hasil penelitian, dapat
disimpulkan bahwa Ada hubungan antara
Umur, pendidikan, tingkat pendapatan, faktor
genetik dan lingkungan dengan Derajat Asma
di Rumah Sakit Umum Daerah Andi
Makkasau Daerah Kota Parepare sedangkan
jenis kelamin tidak memiliki hubungan dengan
Derajat Asma di Rumah Sakit Umum Daerah
Andi Makkasau Daerah Kota Parepare.
Disarankan bagi penderita asma sebaiknya

\section{DAFTAR PUSTAKA}

1. Syahira, Indra Y, Miftah A. 2015. Hubungan Tingkat Pengetahuan Asma dengan Tingkat Kontrol Asma di Poliklinik

Paru RSUD Arifin Achmad Pekanbaru.

Pekanbaru: Fakultas Kedokteran; 2015: 25(1-8).

2. Hidayati,P. Naskah Publikasi: Hubungan antara Pengetahuan tentang Pencegahan Asma dengan Kejadian Kekambuhan pada Penderita Asma di Wilayah Kerja Puskesmas Ngoresan Surakarta. [Jurnal Online]. 2015. [Di Akses pada tanggal 14 November 2018] Available at http://eprints.ums.ac.id/ 37850. lebih melakukan pengontrolan terhadap derajat asma yang diderita sehingga derajat asma tidak semakin parah, hal-hal yang dapat dilakukan oleh penderita salah satunya dengan melakukan olahraga teratur dan pasien asma juga dapat memantau tingkat keparahan asma dengan ACT selain itu penyedian obat asma (semprot atau tablet) juga merupakan hal yang dapat mencegah asma semakin berat. Untuk tenaga kesehatan sebaiknya memberikan edukasi kepada pada pasien asma tentang halhal yang dapat dilakukan untuk melakukan pengontrolan terhadap derajat asma dan bagi peneliti selanjutnya diharapkan lebih mendalam lagi dalam melakukan penelitian terkait derajat asma yang dapat dilakukan dengan menambah variabel penelitian maupun membadingkan hasil penelitian ini.

3. National Center for Health Statistics. International Classification of Disease, Tenth Revision (ICD-10); 2010.

4. Data Rekam Medik RSUD Andi Makkasau Parepare. Laporan SIRS Tahun 2017. Parepare

5. Environmental Protection Agency (EPA). an Office Building Occupational's Guide to Indoor Air Quality. Washington, DC; 2007.

6. Widi A et al. Prevalens Asma Tidak Terkontrol dan Faktor-Faktor yang Berhubungan dengan Tingkat Kontrol Asma di Poliklinik Asma Rumah Sakit Persahabatan. Jakarta J Respi Indo; 2013: 2 (53-60). 
7. Notoatmodjo. Promosi Kesehatan dan Ilmu Perilaku. Jakarta: Rineka Cipta; 2007.

8. Wolagole, Lily. Gambaran Pengetahuan dan Sikap Dalam Mengontrol Kekambuhan Asma Pada Pasien Asma Bronkial Rawat Jalan Rumah Sakit Paru Dr. Ario Wirawan Salatiga. Skripsi. Salatiga: Universitas Setya Wacana Global Initiative for Asthma (GINA); 2015. Global Strategy for Asthma Management and Prevention.

9. Wardani, Vani Kusuma. Hubungan Antara Pengetahuan Umum Asma Pasien Dengan Tingkat Kontrol Asma Di RSUD Dr. Moewardi. Skripsi. Surakarta: Universitas Muhammadiyah Surakarta; 2012.

10. Irawan $\mathrm{Y}$, Windi RR. Perbedaan faktor risiko terjadinya asma bronchial pada pasien dengan asma bronkial dan pasien tanpa asma bronkial di poli anak rawat jalan RSUD DR.H.Andul Moeloek Lampung pada Oktober-Desember 2011. Lampung: Fakultas Kedokteran Universitas Lampung; 2012

11. Fattore GL, Santos Carlos Antonio de ST, Barreto ML. Sosioeconomic and Environmental Determinants of Adolescent Asthma in Urban Latin America: an Ecological Analysis. Cad. Saude Publica; 2015: 31(11): 2367-2378.

12. Purnomo. Faktor Resiko Yang Berpengaruh Terhadap Kejadian Asma Bronkial Pada Anak. Universitas Diponegoro : Semarang; 2008. 


\section{LAMPIRAN}

Tabel 1. Distribusi responden berdasarkan Karakteristik Responden terhadap Derajat Asma di Rumah Sakit Umum Daerah Andi Makkasau Kota Parepare

\begin{tabular}{|c|c|c|}
\hline Variabel & Frekuensi (f) & $\operatorname{Persen}(\%)$ \\
\hline \multicolumn{3}{|l|}{ Umur Responden } \\
\hline 26-45 Tahun & 24 & 24,0 \\
\hline$>45$ Tahun & 36 & 36,0 \\
\hline Total & 60 & 100,0 \\
\hline \multicolumn{3}{|l|}{ Jenis Kelamin } \\
\hline Laki-laki & 27 & 27,0 \\
\hline Perempuan & 33 & 33,0 \\
\hline Total & 60 & 100,0 \\
\hline \multicolumn{3}{|l|}{ Pendidikan Terakhir } \\
\hline Pendidikan Tinggi & 28 & 28,0 \\
\hline Pendidikan Rendah & 32 & 32,0 \\
\hline Total & 60 & 100,0 \\
\hline \multicolumn{3}{|l|}{ Tingkat Pendapatan } \\
\hline Tinggi : $\geq$ Rp.2.600.000 & 42 & 42,0 \\
\hline Rendah : <Rp.2.600.000 & 18 & 18,0 \\
\hline Total & 60 & 100,0 \\
\hline \multicolumn{3}{|l|}{ Faktor Genetik } \\
\hline Ada & 30 & 30,0 \\
\hline Tidak Ada & 30 & 30,0 \\
\hline Total & 60 & 100,0 \\
\hline \multicolumn{3}{|l|}{ Lingkungan } \\
\hline Mempengaruhi & 40 & 40,0 \\
\hline Tidak Mempengaruhi & 20 & 20,0 \\
\hline Total & 100 & $\mathbf{1 0 0 , 0}$ \\
\hline
\end{tabular}

Sumber: Data Primer (2018)

Tabel 2. Hubungan Umur dengan Derajat Asma yang dilakukan di Rumah Sakit Umum Daerah Andi Makkasau Kota Parepare

\begin{tabular}{|c|c|c|c|c|c|c|c|}
\hline \multirow{3}{*}{ Umur Responden } & \multicolumn{6}{|c|}{ Derajat Asma } & \multirow{3}{*}{$\mathrm{P}$} \\
\hline & \multicolumn{2}{|c|}{ Asma Berat } & \multicolumn{2}{|c|}{ Asma Ringan } & \multicolumn{2}{|c|}{ Total } & \\
\hline & $\mathrm{n}$ & $\%$ & $\mathrm{n}$ & $\%$ & $\mathrm{~N}$ & $\%$ & \\
\hline Dewasa & 3 & 12,5 & 21 & 87,5 & 24 & 100,0 & \multirow{3}{*}{0.000} \\
\hline Lansia & 31 & 86,1 & 5 & 13,9 & 36 & 100,0 & \\
\hline Total & 34 & 56,7 & 26 & 43,3 & 60 & 100,0 & \\
\hline
\end{tabular}

Sumber: Data Primer (2018). 
Tabel 3. Hubungan Jenis kelamin dengan Derajat Asma yang dilakukan di Rumah Sakit Umum Daerah Andi Makkasau Daerah Kota Parepare

\begin{tabular}{lccccccc}
\hline & \multicolumn{6}{c}{ Derajat Asma } \\
\cline { 2 - 7 } \multicolumn{1}{c}{ Jenis Kelamin } & Asma Berat & \multicolumn{1}{c}{ Asma Ringan } & \multicolumn{2}{c}{ Total } & \multirow{2}{*}{$\mathrm{P}$} \\
\cline { 2 - 7 } & $\mathrm{n}$ & $\%$ & $\mathrm{n}$ & $\%$ & $\mathrm{~N}$ & $\%$ & \\
\hline Laki-laki & 15 & 55,6 & 12 & 44,4 & 27 & 100,0 & \multirow{2}{*}{0.875} \\
Perempuan & 19 & 57,6 & 14 & 42,4 & 33 & 100,0 & \\
\hline \multicolumn{1}{c}{ Total } & 34 & 56,7 & 26 & 43,3 & 60 & 100,0 & \\
\hline
\end{tabular}

Sumber: Data Primer (2018).

Tabel 4. Hubungan Pendidikan Terakhir dengan Derajat Asma yang dilakukan di Rumah Sakit Umum Daerah Andi Makkasau Daerah Kota Parepare

\begin{tabular}{cccccccc}
\hline & \multicolumn{6}{c}{ Derajat Asma } \\
\cline { 2 - 7 } Pendidikan Terakhir & \multirow{2}{*}{$\mathrm{P}$} \\
\cline { 2 - 7 } & Asma Berat & \multicolumn{1}{c}{ Asma Ringan } & \multicolumn{2}{c}{ Total } & \\
\cline { 2 - 7 } & $\mathrm{n}$ & $\%$ & $\mathrm{n}$ & $\%$ & $\mathrm{~N}$ & $\%$ & \multirow{2}{*}{0.011} \\
Pendidikan Tinggi & 11 & 39,3 & 17 & 60,7 & 28 & 100,0 & \\
Pendidikan Rendah & 23 & 71,9 & 9 & 28,1 & 32 & 100,0 & \\
\hline Total & 34 & 56,7 & 26 & 43,3 & 60 & 100,0 & \\
\hline
\end{tabular}

Sumber: Data Primer (2018).

Tabel 5. Hubungan Tingkat Pendapatan dengan Derajat Asma yang dilakukan di Rumah Sakit Umum Daerah Andi Makkasau Daerah Kota Parepare

\begin{tabular}{|c|c|c|c|c|c|c|c|}
\hline \multirow{3}{*}{ Tingkat Pendapatan } & \multicolumn{7}{|c|}{ Derajat Asma } \\
\hline & \multicolumn{2}{|c|}{ Asma Berat } & \multicolumn{2}{|c|}{ Asma Ringan } & \multicolumn{2}{|c|}{ Total } & \multirow{2}{*}{$\mathrm{P}$} \\
\hline & $\mathrm{n}$ & $\%$ & $\mathrm{n}$ & $\%$ & $\mathrm{~N}$ & $\%$ & \\
\hline $\begin{array}{l}\text { Tinggi : } \\
\geq \text { Rp.2.600.000 }\end{array}$ & 28 & 66,7 & 14 & 33,3 & 42 & 100,0 & \multirow{3}{*}{0.017} \\
\hline $\begin{array}{l}\text { Rendah : } \\
<\text { Rp.2.600.000 }\end{array}$ & 6 & 33,3 & 12 & 66,7 & 18 & 100,0 & \\
\hline Total & 34 & 56,7 & 26 & 43,3 & 60 & 100,0 & \\
\hline
\end{tabular}

Sumber: Data Primer (2018) 
Tabel 6. Hubungan Faktor Genetik dengan Derajat Asma yang dilakukan di Rumah Sakit Umum Daerah Andi Makkasau Daerah Kota Parepare

\begin{tabular}{lccccccc}
\hline \multirow{2}{*}{ Faktor Genetik } & \multicolumn{6}{c}{ Derajat Asma } \\
\cline { 2 - 7 } & Asma Berat & \multicolumn{1}{c}{ Asma Ringan } & \multicolumn{2}{c}{ Total } & \multirow{2}{*}{$\mathrm{P}$} \\
\cline { 2 - 7 } & $\mathrm{N}$ & $\%$ & $\mathrm{n}$ & $\%$ & $\mathrm{~N}$ & $\%$ & \\
\hline Ada & 21 & 70,0 & 9 & 30,0 & 30 & 100,0 & \multirow{2}{*}{0.037} \\
Tidak Ada & 13 & 43,3 & 17 & 56,7 & 30 & 100,0 & \\
\cline { 1 - 7 } \multicolumn{1}{c}{ Total } & 34 & 56,7 & 26 & 43,3 & 60 & 100,0 & \\
\hline
\end{tabular}

Sumber: Data Primer (2018)

Tabel 7. Hubungan Lingkungan dengan Derajat Asma yang dilakukan di Rumah Sakit Umum Daerah Andi Makkasau Daerah Kota Parepare

\begin{tabular}{cccccccc}
\hline \multirow{2}{*}{ Lingkungan } & \multicolumn{6}{c}{ Derajat Asma } \\
\cline { 2 - 7 } & \multicolumn{1}{c}{ Asma Berat } & \multicolumn{1}{c}{ Asma Ringan } & \multicolumn{2}{c}{ Total } & \multirow{2}{*}{$\mathrm{P}$} \\
\cline { 2 - 7 } & $\mathrm{N}$ & $\%$ & $\mathrm{n}$ & $\%$ & $\mathrm{~N}$ & $\%$ & \\
\hline Mempengaruhi & 27 & 67,5 & 13 & 32,5 & 40 & 100,0 & \multirow{2}{*}{0.017} \\
Tidak Mempengaruhi & 7 & 35,0 & 13 & 65,0 & 20 & 100,0 & \\
\hline Total & 34 & 56,7 & 26 & 43,3 & 60 & 100,0 & \\
\hline
\end{tabular}

Sumber: Data Primer (2018) 